\title{
Narrativa fotográfica Usuarios e intervención del espacio público y la resignificación de los usos*
}

\author{
Kathya Jemio Arnez** \\ Recibido: Enero 15 - Aprobado: Marzo 15
}

\section{Resumen}

Con la aplicación de tres técnicas (análisis fotográfico, encuesta a usuarios y trabajo de campo) se describe cómo la intervención sobre el espacio público ocasionó en la zona estudiada la sobreposición de la transitoriedad peatonal a la recreación turística, a la prevalencia histórica, patrimonial y cultural de Ciudad Botero. Se advierte el protagonismo aplastante de la nueva infraestructura, por sobre la representación del lugar y de los usuarios habituales, que modelan el orden, las prácticas vigentes, los usos, representaciones y oficios cotidianos.

La intervención sobre las estructuras arquitectónicas y urbanísticas de la calle Bolívar y de la plazuela Nutibara introdujo resignificaciones culturales, turísticas y artísticas importantes, aunque la intensificación de la función de tránsito con los diez mil usuarios diarios que llegan al sector por la estación Parque Berrío es entendida en el trabajo, bajo formas de tensión, primero, con ese carácter cultural, segundo con la permanencia de vendedores ambulantes y habitantes de la calle, y tercero, con el paso y el paseo recreativo y cultural, a cuya relación se integra el usuario del sector.

El material fotográfico proviene de la Biblioteca del Metro, del Museo de Antioquia, del AHA, y de la BPP, de colecciones particulares y del trabajo de campo.

Palabras clave: fotografía, espacio público, usuarios.

* $\quad$ Artículo proveniente de la investigación Construcción mediática de la identidad en sociedades desiguales. Narrativa fotográfica (2012), con financiamiento del PCJIC. Grupo de investigación ENFOCAR. Línea de investigación: Cultura, tecnología y sociedad.

** Profesora asociada, Politécnico Colombiano Jaime Isaza Cadavid, Medellín, Colombia. Grupo de Investigación Enfocar. Dirección electrónica: kajemio@elpoli.edu.co 


\title{
Photographic Narrative Users and Intervention of Public Space and New Meaning of Uses
}

\begin{abstract}
With the application of three techniques (photographic analysis; customer survey; and field work), it has been described how intervention on public space caused an overlapping of pedestrian transit over touristic recreation, and historical, patrimonial, and cultural prevalence of "Ciudad Botero" (Botero City) on the studied zone. The overwhelming predomination of the new infrastructure over the representation of the site and frequent users who govern organization, current practices, uses, representations, and daily businesses is noticeable.

Intervention on architectural and urban structures of Bolívar street and Nutibara square brought a new important cultural, touristic, and artistic meaning, although the increase of transit operation with ten thousand users who arrive to the place from Parque Berrío station is understood as tension caused by cultural concentration, by the presence of street vendors and homeless people, and by the recreational and cultural sightseeing to which the user of the area is integrated
\end{abstract}

Pictures are taken from the libraries of Metro, Antioquia Museum, AHA, and BPP, and from private collections and field works.

Key words: Photograph; public space; users. 


\section{Introducción}

El abandono de los primeros vecinos, la prevalencia del inquilinato en los alrededores, el comercio informal y la preponderancia de la función de paso y de tránsito, acrecentados por el transporte masivo, han modificado de manera casi impredecible y no visionada las funciones de recreación y paseo. La antigua población buscó en otros barrios la seguridad que perdía en el casco viejo, mientras que paulatinamente, y después de varios episodios de remodelación durante el siglo XX y del inicio de este, triunfó la idea de progreso que traía la ampliación de calles, el ordenamiento vehicular, el transporte público y la construcción del metro.

La estación Parque Berrío, del metro, se ubicó en el cielo de la histórica carrera 51 (Bolívar) y la Plazuela Nutibara. Por debajo quedó un largo trecho peatonal y una arteria bajo la sombra del viaducto para el creciente número de transeúntes. Los días laborales y los fines de semana, las celebraciones, vacaciones y días festivos, singularizan la cantidad y tipo de usuario que transita o permanece en el espacio público.

\section{EL PROBLEMA DE INVESTIGACIÓN}

Medellín a inicios del siglo XX desbordó en soluciones a los problemas del crecimiento para dar paso a las amplias vías en el sector estudiado. La función de vivienda que había sido predominante cedía lugar a la actividad administrativa pública. Hasta entonces, las casas, según describe Restrepo (1981: 275), de teja, de uno y dos niveles, con ventanales y árboles exuberantes y un patio trasero que colindaba con la quebrada Santa Elena, tuvieron la proporción al ancho de las calles del casco viejo. Poco después, en la década de los treinta, la Sociedad de Mejoras Públicas (Restrepo, 46) promovió la obra de la Plazuela y del Hotel Nutibara. Luego, se intervino y cubrió la quebrada, se compraron terrenos para la apertura de una recta de 20 metros de ancho, de la esquina de la Gobernación (Casa de la Cultura Rafael Uribe) al puente de Palacé. Eran los años en que se abría paso la función predominantemente administrativa.

El embellecimiento del espacio público del sector tradujo, luego, la visión de consagrar la zona turística, rescatar su valor histórico y ofrecerlo a los visitantes, mostrar el valor patrimonial y el sentido cultural. Se reforzó entonces la función turística de recreación, historia, cultura y paseo. La estación Parque Berrío, del metro, multiplicó el número de transeúntes ${ }^{1}$ que van a sus trabajos en las inmediaciones, porque este es el Centro y aquí se originó el mundo laboral urbano, comercial, financiero y administrativo que requiere de vendedores, empleados de limpieza, secretarias, técnicos, supervisores, operarios, cajeros, auxiliares, enfermeros, que es el rango dominante de los oficios de quienes recorren el lugar a determinadas horas.

1 La población del Centro: Un millón de personas pasa cada día, 300 mil trabajan, 110 mil viven, 122 mil estudian. Hay 22.500 establecimientos comerciales, 29 parques y plazas, 12 teatros, 8 museos, 5 grandes bibliotecas, 18 colegios y escuelas públicas, 19 parroquias, 2902 venteros ambulantes regulados en el Centro. Fuente: Gerencia del Centro. Alcaldía de Medellín (2009). 
La ciudad había apostado por soluciones de progreso en el último tercio del siglo XX, con la construcción del Metro. Fue así como se incorporó, al murmullo habitual de las calles, de las bocinas de automóviles, carros y motocicletas, el Himno colombiano que se sobrepone a los demás, y que sale de la estación del metro a las siete de la mañana, de la parte alta que colinda con el tercer piso de los edificios de la carrera.

Como se verá más adelante, el golpe a la conservación privilegiada de un lugar antropológico (Auge. 2000) e histórico fue dado con el levantamiento del viaducto. Grandes bloques de cemento y fierro crearon los andamios, las gradas, los durmientes del Metro que atraviesa el cielo y la antigua carrera Bolívar, dividió la Plazuela Nutibara y con esto, sus usuarios se reinventaron las funciones: unas prevalecieron y otras nuevas comenzaron a ejercerse. La frase de Restrepo (p. 274), había quedado con una visión de futuro muy corta: "Cuando se construyan estas avenidas el paseo de la quebrada Santa Elena va a ser el más importante y el más hermoso de la ciudad, que cruzará por la mitad".

A partir de ese momento era de advertir la tensión entre las funciones históricas, patrimoniales, turísticas y culturales, y la creciente transitoriedad, la actividad comercial callejera, la sensación de inseguridad y la presencia de los organismos de control. Se había establecido una incongruencia entre las aspiraciones de acrecentar las funciones de paseo turístico, y cultural, con la instalación de la transitoriedad masiva.

¿Cómo se representan las tensiones en el registro fotográfico y las reales prácticas vigentes?

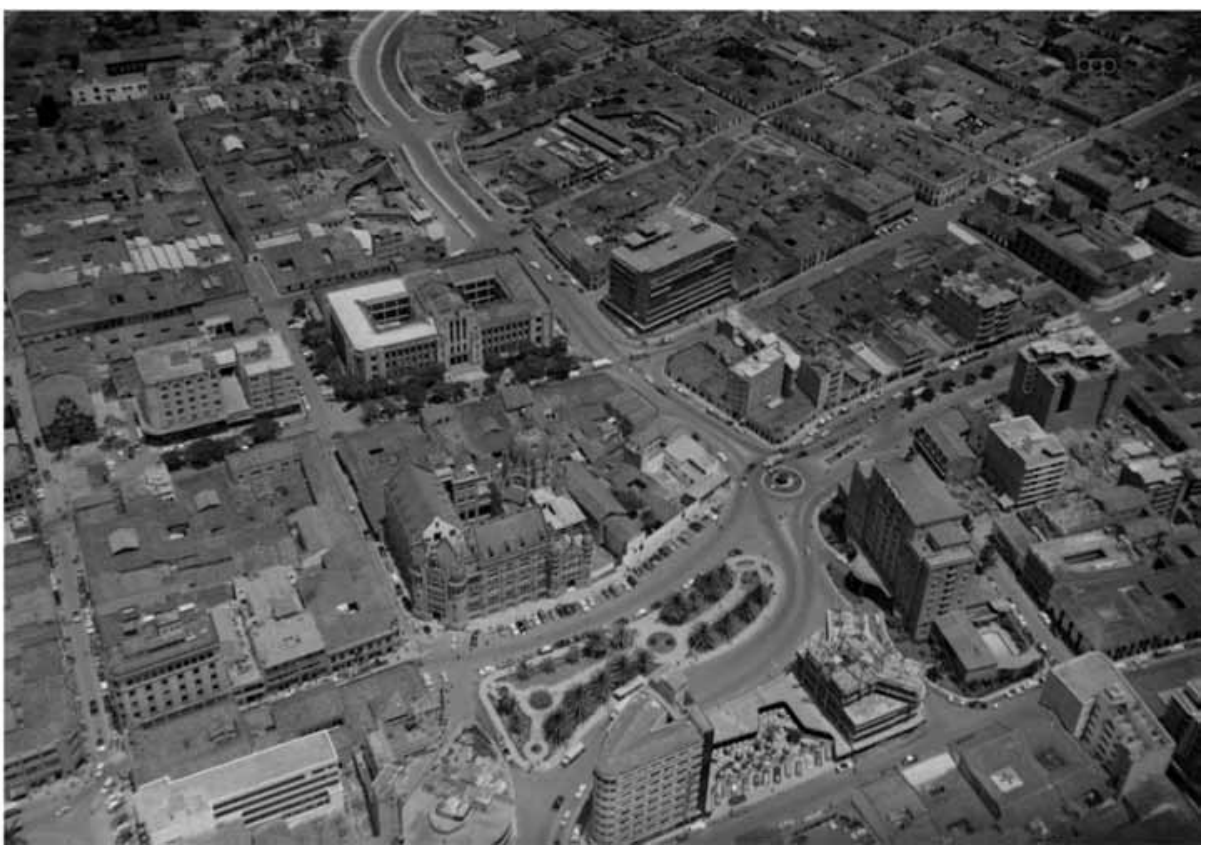

Gráfico 1. Panorámica del sector. Biblioteca Pública Piloto. Catálogo fotográfico 


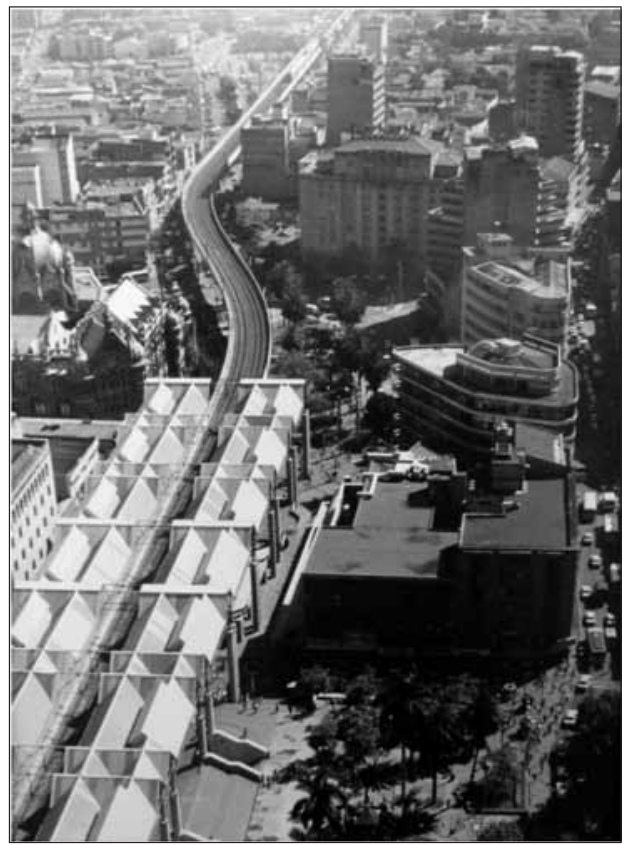

Gráfico 2. Sobre el viaducto Archivo de la Biblioteca Metro. Bello

\section{Marco conceptual}

Uno de los dispositivos de estudio concierne a los cambios en el transcurso del tiempo y a las tensiones que estos producen. Al respecto, Auge (2000, p. 58) entiende que tiempo y lugar son principio de sentido para aquellos que lo habitan, y principio de inteligibilidad para aquel que lo observa, con tres rasgos comunes: identificatorios, relacionales e históricos y cada uno, con un contenido espacial y social de prescripciones y de prohibiciones. Ahí, la tensión en relación con los otros, dada por una materialidad construida y otra conceptual y cultural que, entrelazadas, constituyen el campo de la producción real, como "la experiencia personal y colectiva del espacio y del tiempo, en prácticas y hábitos con resonancias imaginarias, racionales, simbólicas y afectivas" (Castro. 1997: 29-32), son las situaciones cuyo componente es subjetivo.

En el modelo presenta Castro una curvatura, para referirse a la dialéctica entre el transcurso temporal de los fenómenos, los lugares que son habitados y los usos y prácticas; los presenta entrelazados, como las dos caras de una moneda, reconocidas en complemento, tal como sucede con las categorías interno/externo, arriba/abajo, adentro/ afuera y otros binomios. Una de esas dos faces recoge una "cartografía cognitiva", en la que reside la identidad que se resuelve en sitios simbólicos y las funciones están vistas desde el deseo, la representación, la memoria y el conocimiento. También en este lado de la curvatura están los hábitos, las prácticas, la experiencia personal o colectiva, y su valor como referentes del transcurso del tiempo; además, constituyen la trayectoria límite de "centros de poder gravitatorio", material y cultural. La faz externa contiene la produc- 
ción material de lo social, la reproducción del discurso y la producción y reproducción de la visualidad. Ahora, en su transformación presenta: espacios/tiempo que se remiten a una cartografía cognitiva y que están en la representación social, y en cuyo marco lo habitado no solo responde a una ocupación, sino que es reconfigurado y reconstruido regularmente y esto establece relación con un conjunto no pequeño de actividades que se asienta en procesos de representación. En ese sentido, Zunzunegui (1998: 58) aprecia la distinción de los conceptos de representación y de semejanza. La representación no está en la relación de semejanza que pueda establecerse entre el objeto y su representación, sino en que ambos cumplan la función de sustitución. Y como tal precisa dos condiciones: que la forma autorice el significado con el que se le inviste y que el contexto fije el significado de manera adecuada: representación como sustitución. Barthes (citado por Suárez. 2008: 32-34) entiende que la representación no se define por la imitación, a causa de la identificación profunda entre representación y significación. Señala tres aspectos: la cosa representada no tiene que sustituir ni existir de hecho en el momento en que el signo la represente; el acto de significación es autónomo y debe existir un código que establezca correspondencia.

\section{Metodología}

La ficha de la fotografía fue elaborada con sujeción a los objetivos de describir y relacionar las intervenciones urbanísticas con los cambios sociales. Los archivos fueron seleccionados por semejanzas y diferencias. Así, se cruzan criterios vinculados a los oficios, usos y usuarios, y a los cambios físicos. Se definió un tipo de catalogación -procedencia, año, contenido, estado-, luego de la clasificación y categorización. La etapa de análisis e interpretación se adelantó con una plantilla elaborada para este fin. El procedimiento se inició con el estudio de cada unidad, para luego pasar a examinar los detalles por cuadrantes. Una segunda etapa exigió registrar el tiempo, el lugar, los oficios, los usos y los usuarios. Luego la interpretación, en el paso siguiente, exigió recoger tres cualidades relacionadas con la búsqueda pretendida. Finalmente, se describieron el plano, el color, la iluminación, el encuadre y la profundidad de campo. Con ese antecedente se analizó la información por unidad, y todo ello concluyó en una matriz que condujo a la interpretación.

No obstante, de lo esencial de lo visual, el análisis tuvo auxilio del trabajo de campo y de la encuesta para fines de interpretación. La observación participativa estuvo dirigida a la recopilación de información con una ruta de acción; se recolectaron los tipos de material mencionados con la condición de horarios. Los grupos fueron observados, los espacios fueron identificados y organizados por cuadrantes de estudio y observación, según el tipo de oficio y de usuario. La observación fue intencional y contó con la guía que privilegió la relación del individuo con el espacio y la cultura².

La técnica de observación participativa facilitó el levantamiento de datos in situ mediante parcelación. Se hizo el recorrido de acuerdo con calles y carreras, y la recolección

2 La guía tomó la ruta de Marc Auge, quien encuentra en los espacios públicos un lugar de identidad, de relación y de historia. 
de datos puerta a puerta. Se cuantificaron usuarios, habitantes, negocios, empleados, funcionarios, vendedores ambulantes, habitantes de la calle y otros. Este trabajo aprovechó la circunstancia para cuantificar la percepción acerca de las estructuras y dinámicas del sitio y sus proximidades con la técnica de la encuesta.

La comunidad impactada con el desarrollo de la propuesta ha sido identificada como los ciudadanos del Centro, y proviene de la población que proporciona la Gerencia del Centro (Alcaldía de Medellín, 2009). Cada dato se consideró un estrato de acuerdo con sus cualidades particulares, y la encuesta fue del tipo de muestreo aleatorio estratificado con la afijación proporcional: usuarios del transporte (Metro. Afluencia 2010), acopio de taxis y buses (Secretaría de Transporte y Tránsito, junio 2010) en un día, residentes (Comunicación privada, 2010), habitantes de la calle³ , venteros ambulantes (Espacio Público, 2010) negocios y funcionarios.

El formulario de 20 preguntas, dirigidas a los aspectos de espacio, tiempo, organización, orden, tolerancia, vigilancia, control, usos, oficios y lugares se aplicaron durante el primer semestre de 2011. Los límites estuvieron marcados por la Comuna 10 o de La Candelaria. La fórmula permitió determinar el tamaño de la muestra en una cantidad de 200 encuestados.

El itinerario de exploración reconoció, en la dimensión pública, la descripción de oficios y usos. Se hizo registro visual, así como diario de campo. Las unidades de observación (Auge, 2000, p. 19) han sido consideradas bajo la definición de categorías y subcategorías. Las primeras tienen componentes tales como el otro, el tiempo, el espacio, el ego, organización y orden. Las segundas: género, filiación, parentesco, linaje, alianzas, niveles, cultura, cuadrante, vereda y otra agrupación. Las subcategorías del tiempo comprenden la inscripción de los principios de identidad, gusto por las formas antiguas, desciframiento de los sentidos del pasado en el presente (Auge, 2000, p. 36). El espacio comprende: aceleración del transporte, concentraciones urbanas, cultura localizada, vías, rutas, empalmes, caminos, centros comerciales, campos de tránsito, desplazados, multiplicación de referencias imaginadas e imaginarias. El ego comprende: producción individual de sentido. Los lugares antropológicos comprenden: acciones (viven, trabajan, defienden, pasean, vigilan, venden, roban, pasan, marcan territorio, cuidan fronteras), percepciones, actitudes, geografía íntima y fronteras. La categoría "organización" dispone de plano, hábitat, reglas de residencia y paso, geografía religiosa, geografía económica, social, política, orden coercitivo. Finalmente, el orden dispone de la marca social del suelo, refundaciones y relatos de fundación.

El acompañamiento de la técnica de observación aclara cualidades y propiedades del objeto y aporta con significados al reconocer en lo cotidiano el marco social y cultural, vivido e inadvertido. A esa invisibilidad que es señalada y visibilizada pertenecen las jerarquías, los usos discriminados, los valores sociales, el poder, la vigilancia, la estética y el control. De tal manera que fotografía y observación revelan las relaciones: "una foto nunca es ingenua, dice exactamente lo que debe decir, es una ventana hacia adentro, es

3 Cifra obtenida de tres fuentes del sector: Luz Marina Duque Piedrahíta, directora de la Corporación Rescatando Valores, Mirelia Isaza, operaria de baños portátiles del sector La Veracruz y Espacio Público. 
desnudarse ante ojos extraños" (Suárez, 2008, p. 24-25). Es un producto social, que traduce las relaciones, y las conductas observables. "En el análisis cuidadoso y sistemático de un conjunto de imágenes, no es difícil reconstruir el sistema de valoración y jerarquía que guía al fotógrafo en el momento de la toma"; a quien (destinatario) muestra esa realidad socialmente construida y legitimada, "construye una historia y coloca a los personajes donde cree que deben estar (...)".

El principio de realidad produce una situación "tal cual", y la evidencia converge en dos conceptos: el contexto social (studium) que por la participación del fotógrafo, el lugar, el tiempo y el destinatario fluye la evocación y con esto, el sentido que se le da es descodificado y, en el mismo contexto permite entenderla culturalmente, a su autor, sus intenciones y la relación entre creadores y consumidores, y las funciones: informar, representar, sorprender, hacer significar; y la marca (punctum) de lo que evoca, de acuerdo con Barthes (citado por Suárez, 2008, p. 32-34).

Por lo tanto, revela en sus elementos, sistemas de sentido y modelos culturales: valores, normas de comportamiento, orientaciones, jerarquías sociales y otros. En este marco, hay dos categorías de análisis, provenientes de Hiernaux: el continente (conjunto de rastros sociales y culturales que traducen el sentido) y el contenido que son las estructuras mismas, en el fondo de las manifestaciones.

\section{Análisis fotográfico}

Gabriel Carvajal Pérez (foto 1) presenta en esta panorámica, calles, carreras y el sentido de las vías; da una visión de lo que era en 1956: el concepto es de amplitud como describió Restrepo. Era la zona en la cual se concentraban las autoridades, tanto del municipio como del departamento. La construcción del metro presentará después (foto 2), el estrechamiento del que se había liberado a inicios de siglo, la sombra que remplazaría al cielo abierto, y la claridad diurna desaparecería de amplios tramos de la plazuela, y los antiguos frontis dejarían de exhibirse. En la panorámica de 1956, se ven en pie las edificaciones que luego fueron remplazadas por la Plazuela de las Esculturas.

Los referentes urbanos amplios están asociados en su origen al uso para encuentros tradicionales masivos. En la foto corresponde a uno religioso (foto 3). El registro proviene aproximadamente de 1959, el fotógrafo es Gabriel Carvajal Pérez. Es una procesión de Corpus Christi y se observa al fondo el Hotel. El plano es general. La asociación con lo público tiene énfasis en las referencias urbanas, amplias avenidas, edificios y usos públicos masivos. Lo evidencia la sombra colonial que recorre las creencias, frente a una transición urbana altamente marcada por intervenciones urbanísticas como el cierre de la quebrada Santa Elena. Entre los usos distintivos se encuentra la manifestación religiosa que trae consigo un sentido de recorrido que no es el de transeúnte, pues el acto imprime de sentido cultural, religioso y eclesiástico el momento de su paso, no solo una vez, sino reiterativo, periódico, coincidente muchas veces, con las celebraciones del calendario. 


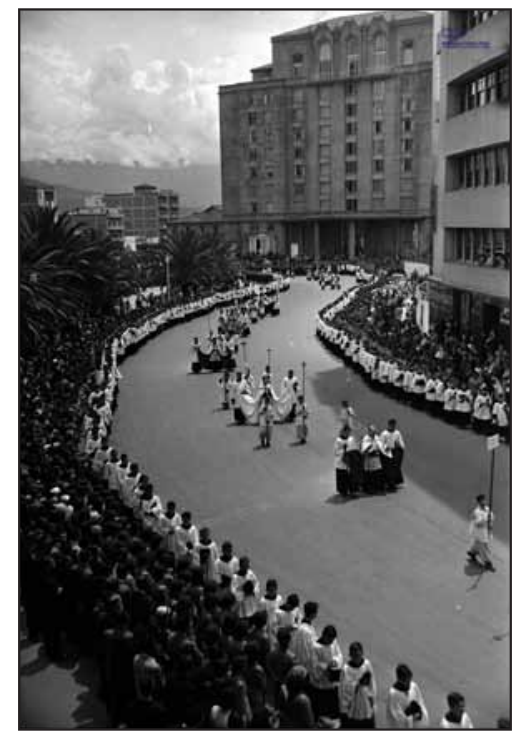

Gráfico 3. Procesión religiosa: Biblioteca Pública Piloto. Catálogo Fotográfico.

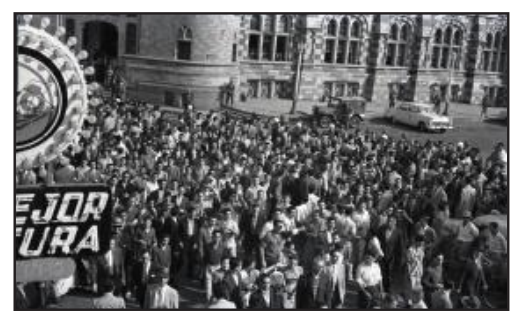

Gráfico 4. Manifestación: Archivo Histórico de Antioquia AHA

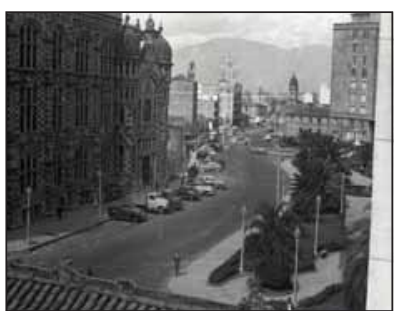

Gráfico 5. Plazuela Nutibara: Archivo Histórico de Antioquia. AHA

El documento (foto 4), obtenido en el AHA (de 1957 aproximadamente), cuyo autor es Carlos Rodríguez, presenta una manifestación distinta. Muestra un plano de la carrera Bolívar junto al Palacio de la Cultura y la Plazuela; la iluminación es natural; hay una manifestación política; el encuadre permite analizar la clase de asistentes, en su mayoría hombres y autoridades custodiando lo que era la gobernación de Antioquia; personas dentro de la edificación observan lo que acontece en el espacio público; hay una propaganda, y la presencia de los organismos de control crea una barrera con la multitud; dos autos parqueados en la acera, y militares en alerta dan cuenta del poder político subyacente. De la situación se infiere inconformidad. Las fotos de estas décadas muestran una significativa aparición de automóviles parqueados en los alrededores de La Veracruz, de la Plazuela Nutibara y en el tramo comprendido entre el Hotel y Carabobo.

El documento (foto 5) del Palacio de la Cultura y de la Plazuela pertenece a un álbum donado por Jaime Osorio. Representa el año de 1955 y tiene una dimensión de seis por 
ocho centímetros. Se ve la parte superior del Palacio, edificaciones, publicidad, vehículos, cableado eléctrico y postes de luz, transeúntes y al fondo la montaña sin poblar, y parte del cielo; la cúpula de una iglesia, transeúntes, la parte derecha del Hotel sin la construcción del restaurante, edificaciones que colindan con su lado posterior; no obstante, por sobre todas las cosas se ve la armonía entre el orden y la amplitud de los espacios de la plazuela Nutibara, sus jardines y palmeras, y se advierte su protagonismo.

Más luego, el sector resistió el embate de factores económicos y políticos, la violencia y el desplazamiento. Entre los años 70 y 80, esta condición se tradujo en el lugar, en la demanda de miles que llegaban en busca de oportunidades. Entonces, la armonía, de actividades, usos residenciales, religiosos y comerciales, se quebró, con la asimilación desordenada de usuarios; sumado a esto, estaban las nuevas edificaciones y la intervención con ampliaciones y arreglos de vías.

\section{Residencia de los usuarios habituales}

Ese cambio todavía se advierte en la lejanía barrial y comunal de los encuestados que se hallan regularmente en los alrededores de La Veracruz, calle Calibío, Plazuela de las Esculturas, proximidades del Palacio de la Cultura, en las cercanías del viaducto: de los doscientos que respondieron, solo un $28,5 \%$ vive en el Centro y proximidades: Veracruz, Guayaquil, Prado, Pasaje Carabobo, Buenos Aires, Avenida Oriental, Boston, Enciso, Aranjuez, Castilla, La Milagrosa, Manrique, Villa Hermosa; un 15 \% vive en barrios de estratos 1, 2, de algunas comunas como la Nororiental, Santo Domingo, Popular 1, 12 de Octubre, Villa del Socorro, Villa Niza, Popular 2, Santa Cruz, Pedregal, Mirador del 12, Picacho; un 15,5 \% proviene de Robledo, San Javier, Calasanz, Santa Mónica, Andalucía, Floresta, Los Colores, Laureles, Velódromo, Santa Lucía, López de Mesa, y un 20,5%, de municipios próximos como Sabaneta, La Estrella, Copacabana, Caldas, Itagüí, San Pedro, Envigado, Bello.

\section{Oficios predominantes, seguridad y vigilancia}

La calidad como sector residencial retrocedió. Aparecieron oficios relacionados con el comercio formal e informal que no siempre generaron mejoras; la zona comenzó a ser asociada a caos, desorden, delincuencia, prostitución, aunque, en menor medida, también a los servicios de las entidades públicas allí asentadas. No en vano la encuesta arrojó que los usuarios se encuentran allí por diversas razones. Un 58,2 \% trabaja en el sector y el 5,0 \% lo visita.

La construcción del Metro ha transformado los usos y oficios del sector. La función de recreación y paseo que tuvo la Plazuela Nutibara ha sido superada por la de tránsito, por la de paso. Cientos de miles llegan o parten de esta estación en las horas de servicio en un día. Este servicio está acompañado del transporte de buses y taxis que tienen acopio en la acera del Hotel, bajo el viaducto y frente a la Casa de la Cultura Rafael Uribe. Este flujo vehicular está acompañado de autos y motocicletas particulares. 
Según la Secretaría de Tránsito pasan diariamente 28.195 usuarios de la estación Parque Berrío; la cifra se triplica con los que provienen del empleo multiplicador de las doce (12) líneas de bus que tienen estación en las aceras colindantes y los tres acopios de taxis establecidos.

Hay vigilancia continua las 24 horas. La presencia y la exhibición de implementos de choque y la movilidad sobre patrullas vehiculares y motocicletas policiales que controlan como en un territorio plano vigilan desde cualquier lugar hasta cualquier otro. Esto lleva a inferir los altos niveles de inseguridad del sector, y/o la necesidad de menguar esa percepción. La policía y Espacio Público acompañan a los turistas o extraños de la zona mientras realizan el recorrido histórico, cultural, patrimonial y turístico. Mediante radio se intercomunican para hacer seguimiento a los ya conocidos (foto 7) con actividad delictiva en las proximidades del viaducto, la Plazuela Botero, en el sector de la calle 53, frente al Hotel y otros aledaños.

El sector durante el día mimetiza y hace invisibles, entre los transeúntes y ambulantes, a los habitantes de la calle, quienes se mantienen durante el día en los sectores próximos con vigilancia permanente.

Los transeúntes y ambulantes se definen en el sector por la realización de acciones concretas, en las que se pueden distinguir razones de paso o de itinerario. Esto no se evidencia con los parroquianos asiduos, en quienes se advierte que no disponen de un oficio o derrotero (foto 8). Los turistas y visitantes evidencian inseguridad y prisa por alejarse. Esto se refleja en su opinión: frente al temor que puedan sentir, revela un 41,3 $\%$ de los 200 encuestados que lo siente sin haber sufrido alguna mala experiencia en la zona; no obstante, cerca de la mitad de ellos $(23,9 \%)$ ha tenido problemas. A pesar de esta sensación de inseguridad, hay otras razones que cuentan para permanecer: les gusta por su oportunidad para hacer negocio, y porque está ubicado en el Centro.

Los organismos de control tienen actitud de alerta y de conocimiento de la inseguridad de la zona. En la vía, un heladero descarga su mercadería, próximos se sientan en una acera dos vendedores de chance y lotería. Pasa una patrulla, pasa un vendedor de cables, controles de Tv, linternas, encendedores, tijeras, sombreros y repuestos diversos. En la estrecha calle cerca al acopio de taxis bajo la estación, se improvisó un estacionamiento de motocicletas. Gente apoyada en los pilares del viaducto, fuma y conversa por celular en actitud de espera. Algunos edificios antiguos permanecen firmes y no fueron afectados por la intervención imparable. Uno de ellos es el edificio Henry que hoy tiene un face to face con el Metro que le impide proyectar en el entorno su arquitectura e historia. En su entrada tiene una gran fotografía que reivindica su pasado de amplio frontis. El sol parte la media mañana.

Sobre la misma cuadra, está la entrada al pasaje comercial Veracruz y tiene en lo alto un puente que hace conexión con la estación. Durante el día, alrededor de 25 uniformados de la Policía Metro vigilan la zona. En la noche son menos. Su tarea es reforzada por la 
Policía de la Candelaria y la Policía Turística, los bachilleres (Policía Bachiller), funcionarios de Espacio Público y vigilancia privada.

Al aproximarse el mediodía hay una especie de hormigueo. Quien observa advierte bajo el viaducto un inusual movimiento hacia todos lados, que se convierte por momentos en una encerrona. La sombra horizontal que se adormiló desde su construcción está sobre la antigua plazuela a la que le cambió belleza, amplitud, y días soleados; esta quedó cortada y oscurecida, y su función de paseo casi desapareció. Al frente, aún bajo el viaducto, entre Boyacá y Calibío, el acopio de taxis congrega a vendedores de tinto, periódico, lotería y minutos celular.

No obstante, se observa que el sector contiene no solo actividades productivas o de tránsito, delincuencia o vigilancia, organización y control, sino que el entorno conforma situaciones de comunidad. Los ambulantes y los de oficios interactúan durante el descanso de mediodía con los parroquianos, cambian de rol, por el de ciudadano que descansa y que tiene su pausa de mediodía. Lo mismo se observó entre vendedores, recicladores, habitantes de la calle, vigilantes y Espacio Público.

Ciudad Botero, en su conjunto, está marcada por el ritmo de actividades del día, pero también por la presencia de turistas que llegan con el objetivo de entender las formas culturales locales y el pasado.

El sitio tiene una dimensión de lugar importante, en el que se advierten reglas, normas, organización, control, relaciones, ayudas, lo que re-significa su condición de encuentro para ambulantes, vecinos de inquilinatos, transeúntes, vigilantes y funcionarios que tienen trabajo en el sector.

\section{Amplitud de espacios y estrechamiento}

Un elemento nuevo se sumó cuando los gobiernos nacional y local se embarcaron en la construcción del sistema de transporte masivo, el Metro, que ayudaría a organizar la movilidad en un espacio, que estaba en dificultades para responder a las demandas de los ciudadanos. El tema se discutió a finales de los 70, el metro se aprobó a finales de 1982; en 1984 se contrató su construcción y, tras múltiples dificultades financieras y de otro tipo, fue inaugurada su línea principal en 1995.

El trazado de la estación Parque Berrío cambió el aspecto. El principal efecto fue su acción divisora. Partió en dos una zona que siempre estuvo integrada visualmente y dividió la opinión de la ciudadanía. Las fotos lo evidencian, el paso del Viaducto del Metro por la Plazuela separó el Palacio de la Cultura tanto del Hotel como de la Plazoleta, lo que fue uno de los factores que modificó el uso para actividades políticas, religiosas y artísticas e introdujo nuevos. 


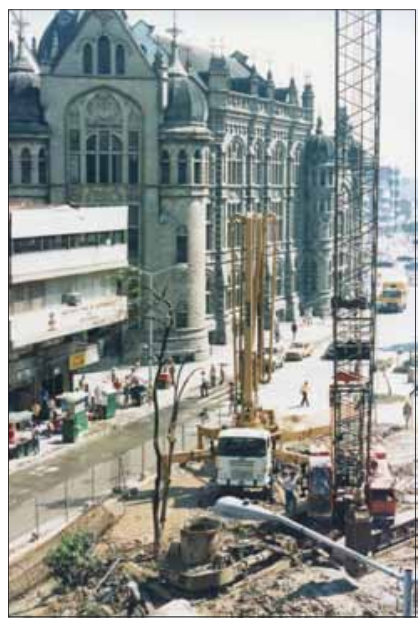

Gráfico 6. Viaducto en construcción. Biblioteca del Metro. Bello

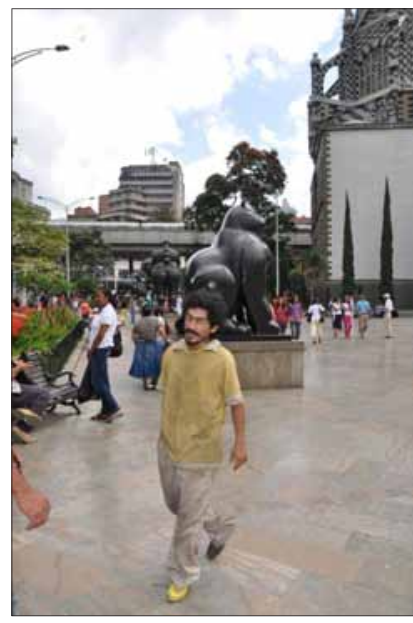

Gráfico 7. Plazuela de las esculturas y el viaducto del Metro. Colección particular

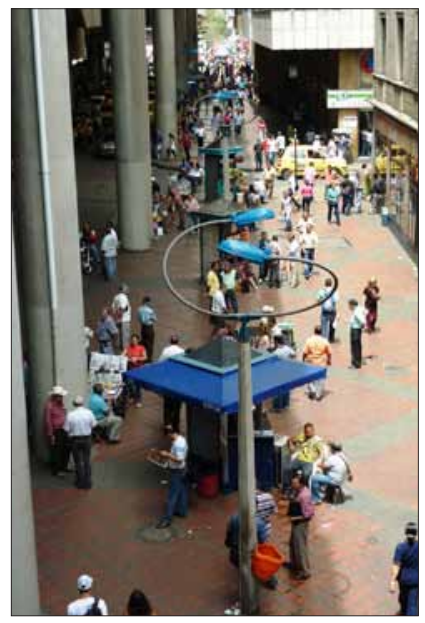

Gráfico 8. Trabajo de campo bajo el viaducto del Metro.

El identificador (foto 6) advierte el inicio de la construcción del Metro en el sector de la calle Bolívar entre Boyacá y Calibío, en la Plazuela. Esta fotografía aborda el proceso de construcción y pertenece a un conjunto realizado con la intención de registrar el avance de obra.

La antigua Plazuela, que quedó dividida, había sido concebida después de muchas transformaciones del sector y de la compra de títulos de propiedad privada para su construcción y para la ampliación de Calibío, ha quedado, después de la construcción, convertida en un zaguán. Se puede advertir en su recorrido, entre otros usuarios, a habitantes de la calle y vendedores ambulantes que permanecen en el sector. En circunstancias concretas aparece en su interior una condición de no lugar (Auge, p. 41) definido como, "las instalaciones necesarias para la circulación acelerada de personas y bienes (vías rápidas, empalmes de rutas, aeropuertos) como los medios de transporte mismos o los grandes centros comerciales, o también los campos de tránsito prolongado donde se estacionan los refugiados del planeta". El espacio del viaducto es ófrico, inseguro y se presta al robo y al asalto. Al 42,8 \% de las personas encuestadas no les gusta el sector por la inseguridad, que, según infieren, proviene de la presencia de los habitantes de la prostitución; el 30,3 \% responde que no le gusta por los ladrones y gamines, y por la falta de limpieza. Algunas de las respuestas están relacionadas con las condiciones físicas, otras a la congestión y otras a las personas que allí transitan. Estas respuestas son aisladas, pero conforman en su conjunto una visión que ingresa a lo que no les gusta.

De los encuestados, cerca del 57 \% dio al sector del viaducto de la estación de metro Parque Berrío una calificación entre regular y mala. La mayor parte de quienes respondieron se encuentra allí durante la mañana y la tarde. 
En los años de su construcción, las máquinas talaron los árboles y se instalaron para la obra. El cuadrante superior izquierdo presenta la parte superior del Palacio Rafael Uribe Uribe y una parte del edificio que colinda después de cruzar la estrecha Calibío. El cuadrante superior derecho muestra parte de la maquinaria y por detrás, en el fondo, parte del Palacio; al fondo de la calle se observa el horizonte y la línea de la vía de tránsito vehicular se mantiene hasta el cruce de León de Greiff. En ese recorrido se observan árboles y automóviles, y la claridad del cielo en las calles que luego, con la construcción del viaducto, se pierde. El cuadrante inferior izquierdo presenta parte de la obra descrita, luego, la calzada vial y al frente la acera en la que se hallan ubicadas las ventas ambulantes y ventas con autorización y sin autorización de Espacio Público, lo que generará después una apuesta por su desaparición. Allí se concentra la mayor densidad de gente que proporciona la fotografía y los comercios formales abiertos; el lado derecho de la parte inferior del material está cubierto por la construcción; es el signo del cambio, el inicio de un proceso que continuará con el levantamiento del viaducto y luego con la inauguración del Metro, no sin antes atravesar una serie de dificultades técnicas, económicas y de administración, y una opinión pública dividida con respecto a su construcción en el lugar.

Es el inicio del cambio, aunque no se advierte la magnitud del mismo. El Centro ha sido siempre motivo de transformaciones, y el usuario lo reconoce, porque supone que son parte de las políticas públicas. Se ve la pronta llegada del futuro y el sueño de progreso mediado por lo físico.

\section{El dispositivo de los cambios}

El identificador (foto 3) registra la Plazuela, hacia el norte. Revela que los autos venían por toda la carrera 51 (Juan del Corral) que era doble vía; hoy, en la calzada a mano izquierda, el sentido es contrario: sur-norte, y a mano derecha es norte-sur. La avenida Primero de Mayo era doble vía; hoy día dispone de un solo carril en dirección oriente occidente. Se ve ya la ciudad muy poblada no solo de viviendas sino también de locales comerciales y grandes avenidas; se observan las calles y su sentido vial, y en las edificaciones más altas sobresale la publicidad; se divisa el barrio Prado, vías, jardines y autos de esos años. Hay edificaciones de más de tres niveles, está la montaña ya poblada; en una edificación de 15 niveles se ve la publicidad, transeúntes, y una de las cúpulas del Palacio de la Cultura Rafael Uribe Uribe.

La fotografía (foto 9) resalta una inmensa réplica de la obra de Fernando Botero en el muro. Allí un hombre vestido de oscuro y camisa blanca, y una mujer de azul claro, pelo oscuro con una delicada moña, bailan con las manos entrelazadas; él lleva entre las suyas, y por encima del hombro, la mano de la mujer; ella extiende el brazo para ese cometido, y juntos avanzan. Por encima del cuadro está inscrito el nombre del pintor. Logra identificarse el patrocinio de la Alcaldía de Medellín. Esta pintura está en un plano de fondo y queda visible en la calle Bolívar, bajo el viaducto. Allí mientras la pareja representa una época, un ritmo, un baile y una clase social, abajo, en la calle, el tumulto transita, y en el fondo horizontal se ve la estructura del Palacio Rafael Uribe Uribe, la plazuela Nutibara 
hasta León de Greiff. El entorno es estrecho y se percibe el hacinamiento. Están algunos puestos de venta y lo más visible es la relación entre las dinámicas sociales y el entorno de la estructura física que se destaca, por un lado, por su historia, y por otro lado, por la Modernidad.

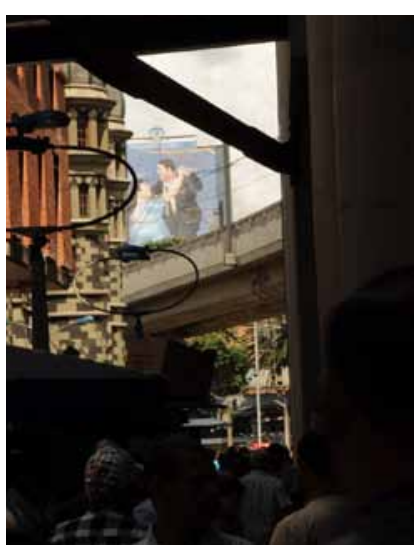

Gráfico 9. Bajo el viaducto. Colección particular.

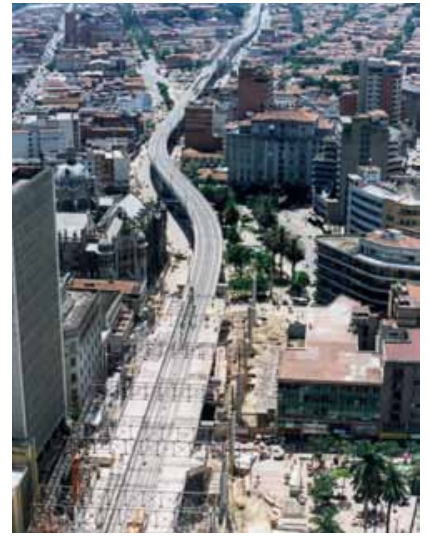

Gráfico 10. Construcción del viaducto sobre la Plazuela Nutibara. Biblioteca Metro. Bello.

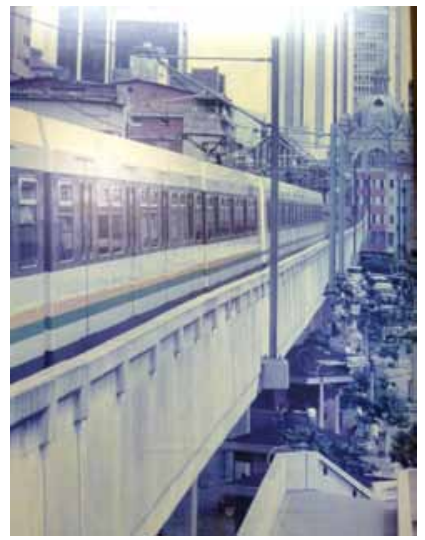

Gráfico 11. Viaducto.

Biblioteca Metro. Bello.

Archivo

El espacio en el que habitan la tradición y la historia, pero también la Modernidad y su complejidad, con un uso regular de las clases populares que recorren el Centro de la ciudad, sintetiza la amalgama de influencias físicas, temporales y sociales y el cambio del uso durante los últimos 50 años.

En la parte superior izquierda se encuentra el paso del metro. Por debajo está la plazuela Nutibara que tiene elementos del pasado, como la fuente, con la estatua de cacique Nutibara, y la estatua del escultor Pedro Nel Gómez. En la mitad izquierda de la fotografía aparece un cartel publicitario de actividades culturales en la ciudad y una señal de tránsito. Los usuarios son pocos. Aparecen las antiguas palmeras que caracterizan la plazuela. En el fondo se advierte el movimiento en la calle León de Greiff.

Hubo desplazamiento de usos. La Plazuela perdió protagonismo durante las transformaciones. Lo que era un ancho paseo, poco a poco se convirtió en ruta de paso, perdió protagonismo, además, con la construcción de la Plazuela de las Esculturas que es el lugar que atrae a los visitantes porque representa cultura y está asociada al reconocimiento internacional del pintor Fernando Botero, pero también, a pesar de ser reciente, representa historia. Hay una especie de nuevos protagonismos en la dinámica física del sector que se advierte en los cambios.

En un plano general, (foto 10) se tiene la intención de evidenciar el avance de la nueva obra, porque resulta el centro de la misma. En la parte inferior izquierda se encuentra el Palacio, enfrente del cual se construye, sobre la plazuela Nutibara, el viaducto. Allí se 
observan las máquinas de construcción. En el cuadrante inferior derecho se observan algunos edificios en el extremo y en el centro las palmeras que perduran hasta hoy. También se encuentra la fuente de la Plazuela, y más allá el hotel Nutibara. Los cuadrantes superiores de la fotografía logran mostrar la construcción de la siguiente estación del Metro en Prado. Se ven en las calles algunos autos, y como la fotografía es panorámica, se pueden advertir las calles y el movimiento que hay.

La modernización del transporte trae en el sector los cambios. Anchas plazuelas y calles que se empleaban para el recreo y el esparcimiento pasan a estrecharse. No obstante del significado trascendental de la estación Parque Berrío para el usuario, él no introduce el tema en sus respuestas. Las razones pueden ser diversas. Sin embargo, esto no deja de lado que para una gran mayoría de la población, el Metro y su construcción han sido signos de progreso y modernidad.

El archivo describe visualmente las transformaciones físicas del sector, unidas a una idea de progreso que trae el metro, como nuevo medio de transporte masivo.

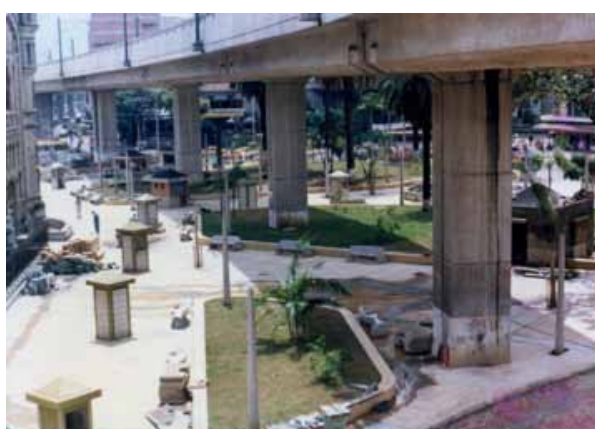

Gráfico 12. Plazuela Nutibara.

Biblioteca del Metro. Bello.

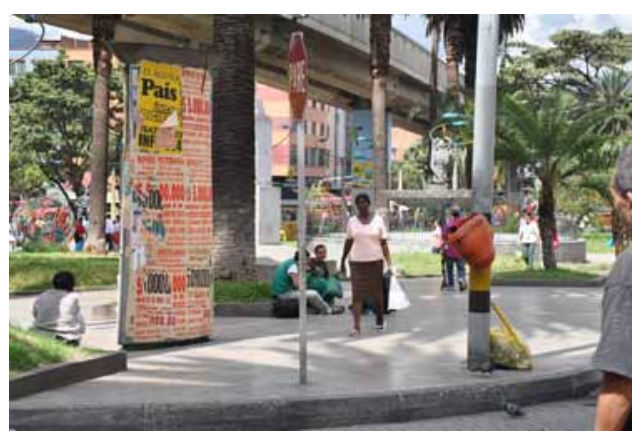

Gráfico 13. Plazuela Nutibara.

Colección particular.

Cambiaron la dimensión, la importancia y las funciones que desempeñó la Plazuela Nutibara durante décadas (foto 12). En el cuadrante superior izquierdo se advierte parte del Palacio; también, la longitud del viaducto del Metro ya construido, el macizo del vaciado y los bloques de cemento. Al fondo se ven las casetas de venta permitidas en la calle; hay escombros de la construcción que se levanta; se ve parte del edificio de la calle del fondo, además de taxis en el acopio de la puerta del hotel; la fotografía representa el proceso de cambio del sector. En el cuadrante izquierdo inferior se ve la construcción de jardines, de casetas, el piso enlosado y peatonal, pues dejó de tener continuidad vial hacia León de Greiff. Hay un nuevo embellecimiento en el sector. Al frente del palacio ya no se divisa sino una franja peatonal. Se trata de un adoquín que remarca nuevo espacio y la nueva configuración de la plazuela debajo del viaducto. Hay asientos de cemento para los usuarios, y alrededor de los pilares del viaducto hay jardinería. Esto nos permite inferir que el sector que comprende la antigua vía de Bolívar no había sido pensado para el tránsito sino para el paseo y la recreación. Hoy en día vemos que estos jardines no 
existen y lo que efectivamente se impuso es la movilidad peatonal desde León de Greiff hasta debajo del viaducto.

El amplio tramo de la calle Bolívar y de la plazuela Nutibara ha sido mermado, y sus usos de recreación y paseo han disminuido también. Pero no solo eso se advierte del protagonismo aplastante de la nueva infraestructura frente a los edificios que otrora fueron los más importantes en dimensión, función y espacio como uso social, cultural, patrimonial e histórico: se evidencia nuevo protagonismo de la estructura física sobre las dinámicas sociales. El patrimonio y la idea de turismo y cultura se subordinan a la idea de Modernidad y progreso, representada en la estructura física. No se revirtió el uso popular del sector. Quedó atrás la época de una comunidad citadina que cedió el paso a la ciudad metropolitana con la conexión de cualquier extremo con el metro.

Aquí se puede concluir que los territorios no son marcados solo por la planificación urbanística, sino que las dinámicas sociales tienen capacidad de imponer funciones. Lo mismo pasó con las casetas que se observan frente al Palacio. Hoy, este lugar es de tránsito de los usuarios del metro, los que atraviesan sin detenerse. Las dinámicas sociales pueden imponer usos preferenciales por sobre las políticas urbanísticas. Un cambio físico puede traer usos impensados durante la modificación. Se apuesta al progreso con la idea del cambio material, sin advertir lo que producirá en las dinámicas sociales. El cambio de usos y el incremento de usuarios del sistema de transporte nuevo acrecientan las oportunidades de transitar. Es parte de la última historia del sector.

\section{Conclusiones}

Las amplias dimensiones de la calle Bolívar y de la plazuela Nutibara han sido reducidas, y sus usos de recreación y paseo han mermado como consecuencia del protagonismo aplastante de la nueva infraestructura, frente a la función y uso social, cultural e histórico que antaño tenían estos lugares.

La plazuela Nutibara perdió protagonismo durante las innovaciones. En principio, fue opacada por la construcción del viaducto del metro. Los nuevos protagonismos en la dinámica física produjeron los cambios en ella, de lo que se deduce que el cambio material afecta las dinámicas sociales.

Es espacio en el que habitan la tradición y la historia ha sido opacado por la Modernidad y su complejidad, con un uso regular de las clases populares que recorren el centro de la ciudad.

Las funciones de tránsito, oficio, paseo, paso y turismo, se han intensificado, aunque en proporciones distintas a las expectativas; se apuesta al progreso con la idea del cambio material, sin advertir lo que producirá en la dimensión de las dinámicas sociales.

A pesar del cambio de la estructura física y el potenciamiento de las actividades culturales (Museo de Antioquia, Palacio de la Cultura Rafael Uribe Uribe), continúa el predominio de los usos y oficios de la clase popular (artistas callejeros, vendedores 
ambulantes). Incluso, muchos de ellos — entre vendedores ambulantes y los que buscan oportunidad de negocio - tuvieron que transformar sus actividades y adaptarse para permanecer. La presencia constante de la Policía evidencia las tensiones entre los usos/ oficios de algunos habitantes, y la seguridad/inseguridad.

\section{Agradecimientos}

A los funcionarios del Archivo del Museo de Antioquia

A los funcionarios de la Biblioteca del Metro. Bello

\section{Bibliografía}

Auge, Marc. (2000). Los No lugares. Espacios del anonimato. Una antropología de la sobre modernidad. Barcelona: Gedisa.

Baczko, Bronislav. (1999). Los imaginarios sociales. Buenos Aires: Nueva Visión.

Candau, Joel. (2006). Antropología de la memoria. Buenos Aires: Nueva Visión.

Chartier, Roger. (2006). El mundo como representación. Barcelona: Gedisa.

Metro de Medellín. (2010). Afluencia por mes y por estación. Afluencia. Medellín: Biblioteca y Archivo del Metro de Medellín.

Museo de Antioquia. Archivo fotográfico. Con derecho de uso de fotografías. Medellín.

Nogueira, Luis Castro. (1997). La risa del espacio. Madrid: Tecnos.

Restrepo Uribe, Jorge. (1981). Medellín, su origen, progreso y desarrollo. Medellín: Servigráficos.

Ricoeur, Paul. (2003). La memoria, la historia, el olvido. Colección estructuras y procesos. Madrid: Trotta.

Sociedad de Mejoras Públicas de Medellín. (1975). Medellín, ciudad tricentenaria. 1675-1975. Medellín: Bedout.

Suárez, Hugo José. (2008). La fotografía como fuente de sentidos. Sociología, fotografía y modernidad.

En: Cuadernos de Ciencias Sociales 150. Costa Rica: FLACSO.

ZUNZUNEGUI, Santos. (1998). Pensar la imagen. Universidad del País Vasco. Madrid: Cátedra.

\section{Archivos fotográficos}

ACEVEDO V., Óscar. (2010). Colección de fotografías del Centro de Medellín. Archivo particular. Medellín.

Archivo Histórico de Antioquia. AHA. Colección de fotografías. Catálogos fotográficos públicos.

Biblioteca del Metro. Bello. Catálogo fotográfico. Con derecho de uso de fotografías. Medellín.

Biblioteca Pública Piloto. Catálogo fotográfico. Con derecho de uso de fotografías. Medellín.

\section{Entrevista}

COMUNICACIÓNN PRIVADA. (2010). Entrevista a Leoncio Angarita, administrador. Medellín. 


\section{Cibergrafía}

FRESSARD, Olivier. El imaginario social o la potencia de inventar de los pueblos. Disponible en Internet: http://www.fundanin.org/fressard.htm Consultado 26.11.10.

SUBSECRETARÍA DEFENSORÍA DEL ESPACIO PÚBLICO. Disponible en Internet: http://www.medellin.gov.co/alcaldia/jsp/modulos/N _ admon/gobiernoespaciopublico.jsp Consultado 22. 09.10.

\section{Investigación}

INFORME FINAL DE LA INVESTIGACIÓN Construcción mediática de la identidad en sociedades desiguales. Narrativa fotográfica (2012). (Sin publicar). Encuesta sobre percepciones, representaciones e imaginarios. (Ciudad Botero). Estudio fotográfico. Medellín: Facultad de Comunicación Audiovisual, PCIIC.

INFORME DE TRABAJO DE CAMPO. (2012). Construcción mediática de la identidad en sociedades desiguales. Narrativa fotográfica. Archivo propio de la presente investigación. Medellín. 